\title{
Online consumer communities and their value to new product developers
}

Article in Journal of Product \& Brand Management · August 2005

DOI: $10.1108 / 10610420510616313$

CITATIONS

95

2 authors:

\section{Dennis A. Pitta}

University of Baltimore

88 PUBLICATIONS 1,290 CITATIONS

SEE PROFILE
READS

259

Some of the authors of this publication are also working on these related projects:

Privacy Issues View project

Linking mathematically formal with socio-organisational Requirements Engineering techniques for high Project quality Information Systems View project

All content following this page was uploaded by Dennis A. Pitta on 17 July 2014. 


\title{
Online consumer communities and their value to new product developers
}

\author{
Dennis A. Pitta and Danielle Fowler \\ University of Baltimore, Baltimore, Maryland, USA
}

\begin{abstract}
Purpose - To explore an emerging area in internet practice that has implications for new product developers.

Design/methodology/approach - The paper integrates concepts including a range of recently published (1993-2004) theoretical works and ongoing case developments in internet practice.

Findings - Provides information and action approaches to new product developers that may increase the success and accuracy of resulting new products. Outlines the benefits of monitoring and participating in online consumer communities and offers practical suggestions for maximizing their value in the product development process.

Research limitations/implications - The theoretical concepts that form the foundation of the paper appear to have a significant application to the product development process but have not been tested empirically.

Practical implications - Uncovers a previously unrecognized source of direct consumer input and cooperation in the design and valuation of new products.

Originality/value - This paper describes the nature and application of online consumer communities to an important marketing process. It offers the potential of improving the success of new products in the marketplace reducing significant waste.
\end{abstract}

Keywords Product development, Internet, Consumer marketing

Paper type Conceptual paper

\section{Introduction: the internet consumer}

The internet has emerged as a truly global means of connecting individuals and organizations. Its nature allows continuous possibilities for transactions. In fact, consumers half a world away, across numerous time zones can engage in commerce with a few mouse clicks. It gives rise to some startling interactions. Now a consumer in Australia can order on Monday from a US-based server across the international date line on the previous day, Sunday. This illustrates one of the internet's benefits: convenience. Users do not have to wait until normal business hours and that convenience enhances the internet's commercial significance.

Internet spending is projected to continue its increase with business-to-business internet transactions representing the majority of commerce. Specifically, Forrester Research reported that business-to-business e-commerce increased from $\$ 406$ billion in 2000 to a projected $\$ 1,823$ billion in 2003. In contrast, the business-to-consumer figures increased from $\$ 64$ billion in 2000 to a projected $\$ 144$ billion in 2003 . Despite business-to-consumer's lower volume, the amounts are still staggering. What is interesting is the emergence of the last variation, consumer-to-consumer e-commerce. Online auction sites such as eBay are perhaps the most well known

The Emerald Research Register for this journal is available at www.emeraldinsight.com/researchregister

The current issue and full text archive of this journal is available at www.emeraldinsight.com/1061-0421.htm

Journal of Product \& Brand Management

$14 / 5$ (2005) 283-291

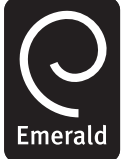

C Emerald Group Publishing Limited [ISSN 1061-0421] [DOI 10.1108/10610420510616313] instance of the consumer-to-consumer phenomenon. eBay earned US $\$ 441.8$ million in 2003, an increase of 77 percent over the previous year, and expects revenue of US $\$ 3$ billion this year. With this rise in consumer acceptance of online trading, has come increased use of the internet to support the purchasing activity. Each of the decisions a buyer faces can be influenced by interactions with communities that are focused on the same product or service type in question. In particular, patient buyers (those who purchase products after making some comparisons) and analytical buyers (those who do substantial research) are increasingly likely to seek out online forums to assist in their purchasing decision. These range from general-purpose sites such as epinions.com to specialized sites dedicated to a segment of a market (for example, avsforum.com is focused on audio visual technologies), or even a specific product type.

For consumers who have already made a purchasing decision, these communities also provide help with the ongoing use of that product. This use can range from seeking help with troubleshooting or repair, to tweaking products to maximize the performance of a product, or the use or integration of the product with others the consumer owns.

This consumer-to-consumer relationship remains an under researched and fertile area in marketing. Relationships between consumers have been shown to influence brand choice (Wind, 1976) and the choice of services, and research has long highlighted the importance of studying the relationships among communicators in the context of interpersonal communication networks (Reingen and Kernan, 1986).

While consumer-to-consumer communication is not new, the organized support and public nature of the internet provides marketers with unprecedented access to information on these communications. At its most informal and unstructured, for example in chat room communications, 
the internet allows researchers access to word-of-mouth (WOM) communication - a form of communications that should not be undervalued. The increasingly popular emerging online forums are particularly advantageous to product developers, however, since they archive and structure these interactions between consumers.

There is some research on consumer-to-consumer relationships in non-commercial environments in which the exchange of money for goods and services is not a primary basis for interaction. For example, research on the shared brand preferences between members of a sorority was found to arise from routine personal interaction rather than commercially based factors (Richins, 1983). Moreover, word-of-mouth information has also been linked to noncommercial sources. Today, such consumer-to-consumer interaction is not limited to face-to-face communication. Online communities of consumers interact to solve problems. Typically, the most vocal and successful problem solvers can be described as lead users.

\section{Communities of interest and communities of practice: definitions}

Communities of interest are groupings of people that have common interests or values, which are able and willing to share knowledge and ideas about their common interest with each other. This interest might be political, cultural, geographical or economic in nature: anything a group of people can have in common. The communities of interest we are interested in are those that are supported by IT via online forum websites, and where the shared interest of the community is related to a product or product group. These forums provide their community members with the ability to participate in the exchanging of ideas, discussion of issues, or the solving of problems, and with access to a repository of knowledge collected by the community over time (the forum archive).

A community of practice is a community that is informally bound by what they do together - from engaging in lunchtime discussions to solving difficult problems - and by what they have learned through their mutual engagement in these activities (Wenger, 1998a). A community of practice $(\mathrm{CoP})$ is thus different from a community of interest (CoI) because a CoI does not require or imply a shared practice. While CoPs are traditionally defined to be within an organization or business sector, and focused on a professional/work relationship, they can also be seen within consumer groups, where those who are engaged in a common practice seek to improve by exchanging information with others. One of the things a CoP produces is a shared repertoire of communal resources (routines, sensibilities, artifacts, vocabulary, styles, etc.) that members have developed over time (Wenger, 1998b). Online forums can support CoPs by hosting these communal resources and enabling communication between members of the community. Such CoPs are often based around a problemsolving goal. For instance, avsforum.com supports groups that are developing technical solutions to AV hardware integration issues. An example is a software project aimed at enabling PC owners to use their PCs as recorders for overthe-air (OTA) HDTV broadcasts.

There is typically a group of members within communities of interest or practice who are interested enough in the group to support and run online forums focused on their interest. Where the interest in is a particular product group (e.g. hi-fi audio) then the developers will almost certainly belong to the lead user category. The most active or frequent participants in the forums will also often belong to the lead user group.

\section{Lead users and the new product development process}

Astute product developers seek consumer input and devote considerable resources to listening to the voice of the customer. Typically customers are not able to articulate desired product benefits well. They tend to be uninvolved with products or services. It therefore falls on the researcher to extract information from research subjects using research techniques. The process can be sophisticated, but it leads to time-consuming iteration. Using the deduced information gleaned from consumers, producers make prototype products for consumer testing. Consumers then use the prototypes and make comments leading to changes in the prototypes. The modified products then are retested leading to more changes and more time investment.

There are two fundamental problems with this approach. First, the experience level, awareness and overall value of randomly selected subjects inhibit efficient product development research. Because they are selected randomly, such subjects may have low involvement with the product. However, if subjects are matched to a target customer segment, their value in the process is usually greater than that of a randomly drawn sample. Second, the research model is deductive and depends on linking statements and responses and then verifying them like a forensic scientist. In a perfect world, consumers would approach companies with requests for specific product benefits, clearly and articulately. That would save considerable wasted time and resources and lead to products which the market accepts.

In the industrial marketing arena, companies have discovered a potentially valuable source of consumer information, somewhat akin to the perfect world scenario. Experienced product users, called lead users or lead customers, can serve as a problem forecasting and problem solving aid. These lead users are often described as educated, knowledgeable employees with considerable experience with a vendor's product. Their key characteristics are interest in and use of the vendor's product on the job. They are involved individuals who use the product extensively and are familiar with its features, advantages and benefits. Their focused set of characteristics makes them a valuable addition to a product development team (Pitta and Franzak, 1996). Lead users also exist in consumer markets and are often members of groups of consumers called communities of interest or communities of practice, as described above.

Lead users offer a more useful approach than randomly selected consumers. They are extraordinary customers. They have been shown to be valuable at several stages of the new product development process. Lead users differ from ordinary consumers in several key areas. First, they tend to have more experience than others. That level of experience brings several benefits. Their familiarity with products may confront the lead user with problems others have not encountered (Herstatt and von Hippel, 1992). Those recognized problems could uncover needed product improvements. By itself, that information is valuable to a creative team.

Second, lead users tend to have more interest in a particular product area than others. That interest may fuel exploration 
and problem solving that may be quite advanced. As individuals, lead users may act like the development teams in their search for new solutions. In fact, they can develop their own "work-arounds" for deficiencies in existing products. Since, as consumers, they are closer to the applications, their solutions may be more valuable than a new product development team's.

Third, lead users tend to apply products to their own specific needs. They extend existing products to new uses that might be commercially relevant to the product's creator. For example, in the 1980 s when executives started using spreadsheets for their managerial work, it was the first time many touched a keyboard. As they learned the value of spreadsheets for analysis, and their experience grew, some started to use spreadsheets as word processors. At the time software companies viewed word processing as the province of secretaries. This new application of spreadsheets prompted Microsoft to add word processing features like spell checking and text formatting in addition to the traditional spreadsheet's number crunching features.

\section{Early identification of trends}

Lead users are usually highly involved in using products for problem solving. In decision-making and information processing terms, they engage in deep and active information processing, making numerous connections among ideas. As a result, they may put products to extreme tests, taking them into areas previously untried. Consequently, such consumers are a potentially rich source of product testing information. They not only can distinguish what works from what does not, but also can provide the reasons why. The notable point may be that they can explain why the problem is significant to them in the first place.

Companies usually cannot anticipate the sometimes idiosyncratic product applications consumers try. Some applications will have no market significance. However, it follows that if companies do not identify new applications, they will not perceive any resulting new markets. Information of this type is vital for staying a step ahead of competition and is one element in maintaining competitive advantage.

Traditionally the new product development process has been conceptualized as including the following major stages:

- idea generation;

- screening;

- economic analysis;

- development;

- test marketing; and

- commercialization.

While lead users can offer valuable input and collaboration in each stage, they are especially valuable in three of these areas: idea generation, screening and development.

Idea generation typically takes the form of unstructured, uncontrolled creation of product concepts. The principle is to create and combine unlikely elements to form a unique and valuable new concept. All of the ideas are supposed to be free of judgment or evaluation since preconceptions inhibit the creation of new combinations of concepts or applications. Psychologists refer to "functional fixedness" as the "box" that constrains creativity (Lilien et al., 2002; Dunker, 1945). Functional fixedness is the human tendency to fixate on the way products or services are normally used (Leonard, 2002). For example, we know that an umbrella is used to shelter us from the rain. It is natural to limit the idea of an umbrella to that use. Free, unfettered ideas have a better chance of overcoming functional fixedness.

Most of the ideas generated are not valuable. Some are comical and have no commercial significance. A recent popular movie depicted a fictional brain stormed idea: feeding mayonnaise to tuna fish to speed up making tuna fish salad. It is an example of a humorous new product idea that is infeasible and has no commercial merit. Still, the goal of the process is not to miss anything no matter how outlandish it appears. Most often the breakthrough idea lies far from the norm. Those breakthrough concepts can be risky. The trend toward product extensions in contrast to entirely new products reflects the quest to avoid risk.

\section{Lead users and idea generation}

Lead users can offer a more focused, immediately relevant influence on idea generation. Based on their interest, involvement and experience, they may be less prone toward functional fixedness. In addition, their ideas may be so well thought out that they are less risky than others.

Arguably their most important potential benefit lies in any problem solutions lead users have already considered or attempted. Their actions may save companies considerable development efforts. Occasionally, experienced users who have considered previously unforeseen applications of products or services to new situations have elaborated new applications. This is another example of the potentially valuable experiential resource that can be exploited by product developers. Their major contribution is a deep understanding of both technical issues and consumer requirements. They can provide the most accurate information necessary to satisfy other consumers. Ultimately, they may be instrumental in developing new product solutions to consumer problems before competition even recognizes them.

Moreover, ideas generated by lead users were found to have enhanced marketplace acceptance (Herstatt and von Hippel, 1992). The reason for this finding may be that lead user preferences are meaningful for their market segment. They can provide detailed understanding that internal product managers can only hope to duplicate. They are also a vocal group of users, and in the case of online communities, have both credibility with their peers and access to a large-scale distribution method for their opinions: this gives them significant potential influence over not only the buying habits of others but what they would like to see in future products.

\section{Lead users and screening}

In general, consumers vary not only in their experience but also in their product involvement. They tend to be astute problem identifiers. In terms of experience, such consumers may have already developed product use habits and shortcuts that improve their performance or save them time. They may have been forced to adapt to a group of products in use on the job or in an avocation and will notice the shortcomings of each of them. Such involved users recognize problems immediately. Apparently minor product features can become serious issues that hamper productivity and may reduce market acceptance. There is no substitute for user input that reflects the complex operating environment found in a 
particular community of practice. These users provide a measure to evaluating product ideas.

In addition to recognizing faults, they tend to generate preferences and wish lists of product features that would make their lives easier. That kind of insight can be highly beneficial in developing new and improved products.

\section{Lead users and development}

The development stage seeks to highlight the benefits of interest to a target audience. Products and services are often described as bundles of benefits and in reality; they deliver their benefits interactively with users. At the concept generation stage, companies design their offerings as a list of component benefits. The problem implicit in this view is the implication that a product is the sum of its components. Products and services are anything consumers think they are. Even if vendors have articulated product benefits accurately, few consumers will recognize them all. Most will value only those components that are particularly important to them and they may ignore the rest. Since lead users represent others like them, they will probably recognize a set of benefits, which are valued by their peers. Findings suggest that tested lead user concepts are valued by more typical users in target markets (Herstatt and von Hippel, 1992). Thus, lead user input can materially improve the market acceptance of new product concepts.

Lead users interested in particular product groups tend to be early adopters, and motivated enough to be a good source of beta testers for products. Manufacturer's seeking real world testing can therefore tap these users more easily than ever before, because those interested will come to them. As an example, TomTom Inc., a company that makes GPS navigation software and is well established in Europe, advertised for beta testers on a US site frequented by those with an interest in a US version of the software. Already a targeted group, those who replied showed themselves willing and interested in testing the product for a number of weeks, and to have good knowledge of competing products available at that time. Several questions regarding their geographic location and existing hardware (brand of PDA, operating system installed, amount of memory, and other GPS software currently used) allowed TomTom to select a group of users for beta test purposes. A free copy of the software and hardware when released was the incentive to users. After a period of non-disclosure those users were free and encouraged to report their experiences on that site, and any other forums. This brought TomTom not only test experience, but publicity from credible users for those looking at adopting the software. Of course this approach is also double-edged: a bad experience would be disseminated as far as a good one. Targeted use of online forums therefore can allow not only product testing, but also an assessment of fit between the product and market. If lead users are lukewarm about a product, chances are their concerns must be addressed in order to be successful within a wider market segment.

In summary, new product developers should seek out sources of lead users relevant to their product or service lines. In the past, identifying industrial lead users has been easier than finding similar consumer lead users. That reflected the ease of identifying larger individual organizational customers as opposed to ordinary consumers. However, the internet has changed things. Now, consumer lead users can be found on the internet with relative ease.

\section{The development of online communities}

The internet fostered communication from its inception. Early in its development, internet chat rooms sprung up which fostered focused interactive conversation. The internet chat rooms led to dedicated discussion forums focused on particular topics. Currently, information technology (IT) allows the easy creation and maintenance of very specific discussion forums. Chat rooms represent a de facto arena that allows individuals to discuss any topic that interests them. By their nature, they allow like-minded individuals to find themselves and to share their mutual interests, learning as they participate. IT allows a range of differentiation and further focus on very specific interests. The topics range from technologically focused forums like internet.com to hobbyist discussion areas. The hobbyist areas might include sports related interests that span the continuum from spectator sports to participative activities like fishing, skiing, golf and many others. Other topics include metalworking, woodworking, travel, financial investment, automobile customization and repair to name a few. In these networks, individuals share their thoughts and gain the insight of other knowledgeable persons. The specificity is remarkable. For example, the fishing topic area might be divided into the variety of fishing subtopics like deep sea, fly casting, fresh water, game fishing and others. It might even specialize on a specific fish species, like bass, trout or marlin. In one-to-one marketing terms, the contact is direct and highly interactive. Over time, as people learn more about each other and the subject, deep personal relationships may form. Given their significance, it is valuable to understand the underpinnings of such networks.

\section{Foundations of an online community}

Initially, the internet fostered a one-way communication stream as companies developed websites to promote their products and services. The internet, a computer-mediated environment, featured communication best described as mass communication. Most organizational websites today feature a rich selection of information links for those interested in using them. As the use of the internet developed, discussion forums began to appear. Discussion forums present a different computer-mediated environment, one with greater interactivity and interpersonal use. In this case, a consumer can post a message to a forum and wait for others to react. The simplest model involves two consumers interacting by each sending their message to a forum.

Over time, this two-way communication gave rise to the notion of the internet as a community of members interacting among themselves. In fact, that notion has been central to the internet from its inception (Hagel and Armstrong, 1997).

While, marketers do not usually adopt a "community" view of their market, they tend to focus on the wants and characteristics of their target market segments. Segmentation efforts by marketers have undeniably been successful over time and have developed into an effective tool in the quest to satisfy consumers. The view of customers as part of a community is central to anthropological research. That research tradition holds that there are preeminent elements defining communities. Historically, they have included:

- $\quad$ sustained social interaction;

- shared attributes, interests and values (community standards); and

- a proscribed geographical area. 
Those elements define cities, towns and villages throughout the world. The definition is limited however and does not include the numerous other communities that exist. For example, university alumni associations and veterans groups may have members scattered around the globe. They can interact via telephone, mail, or e-mail and meet for special occasions.

The internet presents its own geography, which has no traditional geographic boundaries. As a result, more modern research has accommodated the boundless confines of the internet in their definitions. For our purposes, a community exhibits sustained social interaction; shared attributes, interests and values (community standards); and membership rules. These elements are present in "virtual communities," those groups of interacting individuals, which form on the internet. The focus of each community may be technical, social, and economic or a special interest shared among members. These online virtual communities allow that necessary social interaction among members and have either subtle or conspicuous rules of behavior.

Interaction among the members is the engine that fosters the growth of such communities. That interaction is part of a relationship building process that allows individuals with common, and perhaps rare interests, to communicate together in pursuit of those interests (Hagel and Armstrong, 1997). The communication process takes place in a computer-mediated environment that shapes the nature and scope of the information shared. Computer mediated environments (CME's) have some strengths that aid communication effectiveness as well as weaknesses that hinder it. One strength is the use of discussion forums that allow asynchronous communication. The forums' asynchronous nature fosters communication because it avoids having to schedule a time when comments are shared. A user can post comments; others can respond to them later. In addition, the quality of comments may increase, since asynchronicity reduces haste and miscommunication in responses.

In contrast CME's are limited to a subset of communication modes. Until recently, one could use text and graphics, but sound, smell and body language could not be shared. Even now, embedding sound or video clips is ponderous and not available to all. One other drawback is that its asynchronous nature sterilizes spontaneity.

A virtual community depends on combining communication and content to foster the exchange of information. By its nature, the information exchange allows people to learn about each other as they learn more about the community's focal topics. Hagel and Armstrong (1997) have investigated the consumer motivations for joining an online community. They satisfy several needs. Three are of relevance here:

(1) Shared interest.

(2) Relationship building.

(3) Transaction.

Online communities can satisfy all three needs in equal measure or concentrate more on one or another. As Rothearmel and Sugiyama (2001) point out, this can lead to several types of communities. A community of interest is comprised of individuals who share a common interest, hobby or skill set. In a community of interest members will share their experiences, preferences and information about the focal topic. For example, bass fishermen may discuss lures, bait, fishing grounds and gear. The second element, relationship, can lead to a community of relationship. These form around some intense life experience such as the loss of a loved one, a disease diagnosis or other significant event. In such circumstances, consumers may find comfort in the experiences of others and, in doing so, form relationships with them. Over time the relationships become increasingly important. Similarly, a community of exchange focuses on the exchange of information to facilitate economic exchange. Thus, consumers of vintage automobiles or boats can discuss the best repair shops, boatyards and sales sources in a given area. In each of these communities, members share information of value to themselves and others. That sharing can be valuable to marketers. The last variation, a community of practice, focuses around an activity common to the community membership. The community of interest and community of practice models seem to offer the greatest commercial potential.

\section{Nature of and evolution of online communities}

Our model for online communities is based on those communities of interest that surround many hobby areas. Participants interact because they are interested in the topics discussed.

All communities go through stages of development. The Figure 1 details the community development model. Online forums tend to come into being at stage two, when a sufficiently motivated and technically knowledgeable person or group decides to create the forum.

From there the forum may grow, if sufficient numbers of its target community find and adopt the forum. It is sustained if the number of new members is equal or greater to the number who lose interest over time. Over time, forces that foster community formation may operate. Those forces include interests and relationships.

\section{Interests}

The typical online community is a niche. The interest relationship or exchange focus is usually very narrow. Logically online communities satisfy needs not met in faceto-face situations. A member's real community may have a large population with few or no people interested in the same subject. If the focal issue is narrow, the online community will mirror that narrowness and tend toward homogeneity. As a source of market information such online communities can be priceless.

A discussion forum is a unique blend of public and private communication. They make the risk of participating lower. They force individuals who want to participate to register online at no cost, reducing the monetary risk of joining. Registration involves supplying identity and contact information as well as a preferred nickname to preserve anonymity in discussions. Typically, users are asked for a valid e-mail address. When supplied, a registration password is returned to the user's specified e-mail address. This practice serves as a partial safeguard against fraudulent behavior, reducing that risk. Without a valid e-mail address, a user cannot register. Even if the contact information is false, the email address will aid in identifying the user should a problem arise. 
Figure 1 The community development model

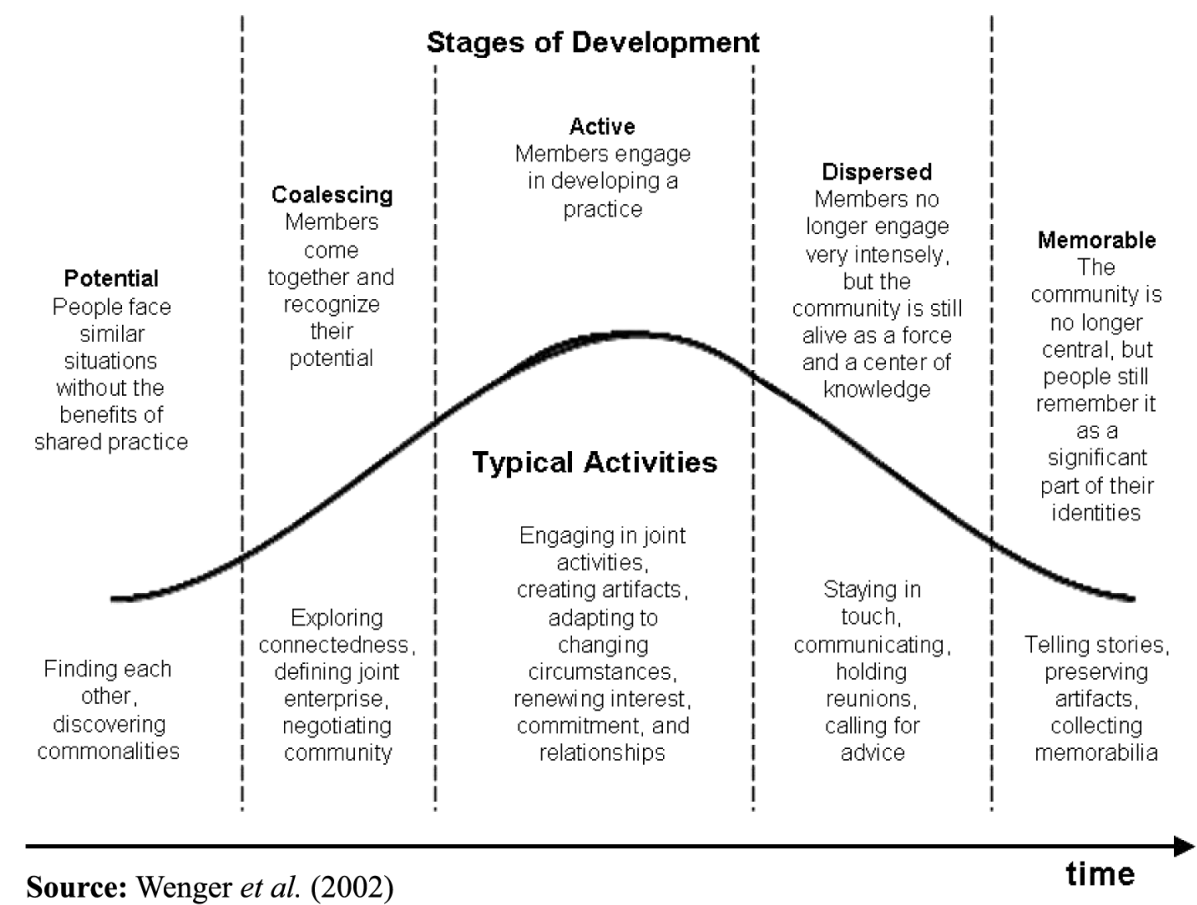

The use of pseudonyms has another benefit. They allow members to recognize the postings of others and to foster a sense of a member's personality. Over time, members form impressions of others, which may reflect their interests, knowledge level, and even the quality of their judgments and their character.

Members may find an online community after an internet search. Their initial interaction may be as a "lurker." Lurkers visit a discussion forum and may initially read the posts and observe without participating actively. The reaction is understandable since learning the group's mores and expectations is important. As individual personalities emerge, new members may become comfortable enough to participate themselves and share their own preferences and interests. Protected by the anonymity that a pseudonym provides, members may divulge information in a public forum that few others may know.

\section{Relationships}

The information sharing process is at the heart of online communities. The key obstacle to sharing is trust. The use of pseudonyms and the public sharing in the discussion tends to build trust over time.

The relationship building aspect of online communities is the basis for consumer-to-consumer networks. The process develops in the following way. Consumers interact in a discussion board focusing on issues of interest. If the community rules provide no barriers to participation, a group of members may start interacting, discussing topics of mutual interest. Over time, other members will read the posts and associate them with their authors. By linking authors to their opinions, judgments and words, members can build an image of other online members.

During the interaction process the members, identified by their names, may post comments directed at a specific member. They may be complimentary or solicitous and they tend to build relationships. Using the private messaging facilities common to most discussion forums, members may contact each other and form their own mini-network of members. Over time the relationships can become strong and members may even travel to meet to socialize.

The information network offers a rich and unparalleled source of information and ideas for marketers. To exploit this source, marketers may wish to use their own pseudonyms and visit the forum to observe its content. By shadowing the forum, marketing personnel can gauge the nature and scope of the interaction that might reveal consumer complaints, suggestions, wish lists, or new ideas. The arena allows an open window to the consumer's expressed opinions, beliefs and preferences. Over time, consumers learn to trust the safety of their group of online friends and divulge more deeply. They witness others sharing information and tend to join in. While it is difficult to estimate the value of this information source it must be considerable.

\section{Lead users and online communities}

Such forums foster the emergence of lead users. The community of interest model provides a non-threatening harbor for members that offers the potential of nurturing knowledge in a particular area. That environment encourages community members to share their wants, challenges and possible solutions to problems and new applications.

Lead users in a community of interest tend to be good problem solvers who are not afraid to share their solutions online within the community. They are easy to identify and their public sharing of solutions allows visitors or community members to assess the value of their ideas. Over time, they emerge from within the community. 


\section{Accessing lead users in online communities}

Despite the early realization that lead users could provide great insight into marketing research, they have provided a great deal of information to aid the new product development process (Miller, 1995; Lilien et al., 2002). Online communities present benefits that a face-to-face focus group cannot.

Discussion forums and online communities present unprecedented opportunities for both passive market intelligence and active market research. Listening to the dialog can alert companies to possible future trends, an example of market intelligence. Verification might require more marketing research. Here the marketer can be more than observer and reporter. Researchers can enter the forum and conduct discrete, focused surveys after determining the characteristics of the members. Beyond survey research, a discussion forum may provide a venue for experimentation. For example, creating "membership-only" offers for a discussion forum is a form of field test that might provide metrics of consumer price elasticity, preference for product features and other valuable information.

Analogously, product developers can exploit the information shared in an online community both passively and actively. Reading lead user's accounts of product or service problems and their solutions can be an inexpensive yet valuable source of ideas.

In a more active manner, companies can join the community and question members about product wants and their evaluation of proposed new products. Thomke and von Hippel (2002) described a trend toward tying into the wants of potential customers more directly. They report that an increasing number of companies have abandoned their marketing research efforts to understand exactly what products their customers want. Typical marketing research employs the familiar focus group or consumer survey that often measures surrogate factors in the hopes of uncovering the key underlying wants or product benefits. In the past, those efforts have either failed to identify key benefits or miscalculated their priority.

To avoid those problems, innovative organizations have chosen a more direct route. They have provided customers with tools to design and develop their own products. Coupled with directions to create products that they would like to see, the results have been valuable. Instead of clues, the organizations can see finished product designs. Thomke and von Hippel report results that range from minor "improvements" to more extensive new innovations. For example, there is a website called adiamondisforever.com. The site is sponsored by The Diamond Trading Company and is very well engineered. Upon entry, users are invited to design their own jewelry and the site provides an interactive design tool. As a condition of entry, the site collects consumer demographic information as well as purchase intention information.

One limitation is that the tool is structured and somewhat like a multiple choice test. The range of possibilities is predetermined. Designing a more unstructured design tool presents challenges but may deliver higher information value. Overall, it is a worthwhile approach limited by its structure.

\section{Sponsorship}

Communicating with relevant online lead users is in some ways easier and in other ways a bit more difficult. Product developers can design, foster, and implement an online community for a generalized, mutually beneficial exchange relationship. The communities create a network of consumer relationships, which divulge a rich and unparalleled source of information and ideas.

While most online communities will be self-organizing, there are ways in which they could be "sponsored." A sponsored community of practice is defined by Nickols (2000) to mean a community that is initiated, chartered, and supported by management. Our meaning is quite different. While communities of interest, and of practice, are resilient in terms of their members coming and going, they are quite fragile with respect to efforts to manage or influence them by those outside of the community (either management, in a company, or in our case by new product developers). If it is done carefully, however, product managers can provide a supporting role for online forums.

In traditional broadcasting sponsorship, the aim is to promote the brand or company image. That goal is accomplished by aiming commercial messages at target consumers. The internet easily adopted sponsorship in the form of pop-up or banner advertising. Integrating IT functionality, online sponsorship allows "click and view" exposure to advertising. Despite the emergence of pop-up ad "killers," such advertising exposure is cheap and offers the potential of delivering a group of self-selected prospects. One fundamental problem with all advertising is its one-way nature. Advertisers can beam messages at an audience but have difficulty gauging their effects, other than sales. If sales response is low, it might be due to the offer suiting only a narrow range of customers. Alternatively, it might be favored by most customers but be flawed by a single element. Perhaps the price is right but the payment terms are not. One-way communication thwarts really understanding the consumer. Ignoring the promotional possibilities, IT and the internet offer a wider way to interact with consumers.

Today, sponsorship entails designing, funding and operating an online forum. The key is to ensure ownership and partisanship of the forum is unaffected. A sponsored community of practice in an organization would be expected to generate tangible, measurable, value-added benefits to the business. A sponsored forum on the other hand must remain neutral, and be seen to be neutral, to the discussions and actions of the community. The online forum is valued by users because of its independence from those with a clearly biased agenda like retailers or manufacturers, and therefore has credibility.

When it is done carefully, however, the involvement of a product developer as a sponsor or co-sponsor can be a winning proposition to the user. The user benefits would include financial support. Financial support can ensure the longevity of a forum. Forums are often started as a hobby by someone with an interest, but with other responsibilities like family and a job. There is no expectation that the forum will last forever. Forums require significant costs. They include bandwidth costs, database servers, forum software, the costs of moderation and others. In general, the more successful the forum is, the higher the costs are. While the community itself 
may donate to its upkeep, membership support may not be sufficient.

Product developers can gain by becoming involved in support of a forum. The developer cannot start the forum - it would likely be seen as biased, and unlikely to attract the community the developer is interested in. A better approach would be to find a community forum in the potential or coalescing stage (see Figure 1), which could benefit from a source of consistent financial support in order to grow and remain viable. The key users/community members that have the motivation and drive to lead the forum development will already be identifiable. These forum champions will remain the driving force in the community, and retain control over the forum itself. The product developer has no direct or active influence over the community, but gains the benefits of being a major sponsor: in addition to access to the knowledge of the community, and the chance to positively influence the attitude of the community toward their products, the developer has a way to identify a consumer lead user as easily as finding an industrial lead user. The community benefits from having direct access to information from the product developer.

Moreover, there may even be test-marketing benefits. By identifying valuable target users, the sponsor might pretest new products and elements of the marketing plan. For example, if online community members emphasized a set of product benefits that were incorporated in the development stage, they could assess how well the company communicated them in the product design and in its promotion. This has the potential of increasing test marketing success and reducing the financial cost of product failure.

\section{Exploiting the potential of online communities}

The psychology of marketing emphasizes that people do things for specific reasons relevant to them. Visiting a discussion forum is totally voluntary and the selection of a discussion to join signals broad consumer preferences. Hobbyists, for example, represent a group of consumers who like a particular subject, product category, pastime or service. Their interest may be focused and overt. They may spend a considerable amount annually on their hobby.

Involving consumers in a hobby-focused forum may generate increasing sales as members communicate with others. One may share an interest that the rest of the community embraces.

If sponsors can provide the forum, free of overt promotion, the community may flourish and benefit the sponsoring organization.

Amazon.com offered consumers chance to write book reviews of their titles. The obvious benefits to Amazon.com include generating word of mouth about its inventory. It does not matter if the review is positive or negative. The reviews give Amazon.com information about consumer preferences in the form of consumer comments about the quality and perceived value of individual titles. Such information signals future consumption trends and aids in refining its inventory holdings.

The consumer benefits include the chance to write something that will appear in public. Amazon.com provides a venue for consumer ideas and judging from the number of reviews, at least some consumers value the opportunity. The example represents a primitive step in the evolution of a consumer network. Properly, it is a clear business-to- consumer (B2C) connection. It lacks the important element of direct interaction among consumers.

\section{Implications for new product development teams}

Online communities offer new product developers a number of potential benefits. It must be emphasized that effective management is vital to realize those benefits. While there are a number of opportunities, they must be handled appropriately or the results will be disappointing.

New product developers should consider finding and sponsoring online discussion forums featuring topics of interest to their customers. The growing numbers of people who use the internet present a growing audience for many marketers. It offers the developer a chance to collect marketing information of significance. Such online communities will attract lead users who will be able to communicate their knowledge to others, including the sponsors. As a result, online communities of interest can provide specific new product ideas that come directly from knowledgeable users and should be accurate and representative. To be effective, the sponsor should refrain from too active and overt a role in an online community. If a sponsoring firm takes too active a role, it runs the risk of inhibiting discussion and the potential for valuable product information.

Any contribution to discussions should be careful to provide useful information, which is either tacitly or explicitly solicited. Trust must be built over time, and can be lost quickly if the community sees the interaction as being solely self-serving. A supported community forum is also more likely to seek a variety of sponsors, to balance bias: representatives of the developer should therefore be careful in comments about competitors. The focus must be to support the community.

Information divulged in the communities can increase the efficiency of the marketing transaction as well as the new product development process. Product managers can get accurate information to create desirable product and service offers, reducing the new product failure rate and increasing chances for success. Market intelligence is relatively easy to obtain. For more purposeful information gathering, new product developers can take a more active role. The communities offer the chance for product developers to interact as members sharing thoughts or presenting potential product concepts for comment. Firms must decide how to handle such information sharing. They face three possible interaction modes: covert, overt and mixed modes. A covert interaction is defined as a "community member" asking questions of the community. In this case the member is also an employee of the firm. An overt interaction identifies the firm and interacts with the community as an outsider. The third mode features both modes. The mixed mode may offer the firm a degree of flexibility while also offering the chance to capitalize on any lessons learned. For example, the covert "community member" might uncover some valuable product related information and in his interaction might verify its nature. Later, the firm might use that information to craft a product concept or new product feature and verify the community's interest.

Sponsored online forums can change the marketingcustomer relationship. An online discussion board can become a source of expertise that turns it into a specialty 
product. That product includes the combination of facts and social interaction that leads to relationship building. There are some online communities in which the sponsor fades into the background, and the members' positive word of mouth creates goodwill. Thus, sharing the information and interacting with the other members becomes important in and of itself. Whatever goodwill the sponsor generates might be used to solidify a marketing relationship with members. Sponsors of popular discussion forums may be able to use the forum not only to gain new product ideas but also to sell the resulting products directly to consumers.

Online consumer communities offer the potential of changing the marketing research function. The forums can be a source of exploratory research, concept testing, product design, delivery preferences, communication research, and even pricing. In addition, since online communities are characterized by a focus, an appropriate choice of a community should increase the validity of any information generated.

Organizational changes may be necessary. The activities involving information gathering, verification and integration into the product development process will require investment of institutional resources. The most valuable resource will be personnel. Internal personnel should be assigned to monitor or perhaps lead discussion threads. Their findings offer potential benefits to the organization. To exploit their value, further changes would involve mechanisms for integrating consumer and lead user preferences in the product development process. Without a clear idea of how to exploit the information that online communities can provide, companies run the risk of missing opportunities.

\section{References}

Dunker, K. (1945), “On problem-solving”, Psychological Monographs, Vol. 58 No. 5.

Hagel, J. and Armstrong, A.G. (1997), Net Gain: Expanding Markets through Virtual Communities, Harvard Business School Press, Boston, MA.

Herstatt, C. and von Hippel, E. (1992), "From experience: developing new product concepts via the lead user method: a case study in a 'low-tech' field", fournal of Product Innovation Management, Vol. 6, pp. 43-50.
Hoffman, D. and Novak, T. (1997), "A new marketing paradigm for electronic commerce", Information Society, Vol. 13 No. 1, pp. 43-55.

Leonard, D. (2002), "The limitations of listening", Harvard Business Review, Vol. 80 No. 1, p. 93.

Lilien, G., Morrison, P.D., Searls, K., Sonnack, M. and von Hippel, E. (2002), "Performance assessment of the lead user idea-generation process for new product development", Management Science, Vol. 48 No. 8, pp. 1042-60.

Miller, C. (1995), “The customer as creator", Visions, Vol. XIX No. 4.

Nickols, F. (2000), "Two kinds of communities of practice", available at: http://home.att.net/ discon/KM/CoPTypes. htm

Pitta, D.A. and Franzak, F. (1996), "Boundary spanning product development in consumer markets: learning organization insights", fournal of Consumer Marketing, Vol. 13 No. 6, pp. 66-81.

Reingen, P.H. and Kernan, J.B. (1986), "Analysis of referral networks in marketing: methods and illustration", fournal of Marketing Research, Vol. XXIII, pp. 370-8.

Richins, M. (1983), "Negative word of mouth by dissatisfied customers: a pilot study", fournal of Marketing, Vol. 47, Winter, pp. 68-78.

Rothearmel, F.T. and Sugiyama, S. (2001), "Virtual internet communities and commercial success: individual and community-level theory grounded in the atypical case of TimeZone.com", fournal of Management, Vol. 27, pp. 297-312.

Thomke, S. and von Hippel, E. (2002), "Customers as innovators: a new way to create value", Harvard Business Review, Vol. 80 No. 4.

Wenger, E. (1998a), Communities of Practice: Learning, Meaning, and Identity, Cambridge University Press, New York, NY.

Wenger, E. (1998b), "Communities of practice: learning as a social system", The Systems Thinker, Vol. 9 No. 5.

Wind, J. (1976), "Preference of relevant others in individual choice models", Fournal of Consumer Research, Vol. 3, June, pp. 50-7. 